\title{
Some observations on underground mining strategies
}

\author{
Y. Potvin Australian Centre for Geomechanics, The University of Western Australia, Australia
}

\section{Abstract}

This paper discusses observations made by the author during the last 30 years, having worked in Canada, USA, Australia, South America and Sweden mining industries in numerous roles including participation in mine feasibility studies, operating mines, review boards and research activities.

Strategic approaches are observed at different levels, from the high level of corporate strategy, which concerns itself with maximising shareholder value, to mine site strategy focussing on maximising the value of a specific asset.

Looking at the life-span of a mining project where one of the company's assets is exploited, the focus shifts from a longer-term outlook of project definition during which scoping and feasibility studies are performed, to the shorter-term problem solving of project execution including the construction and production phase. With this shift in focus comes the temptation to alter or even disregard the original strategy implemented at the early stage of the project. A potential consequence of this is that tactical decisions can become misaligned with the long-term strategy, and the real value of the asset is never realised.

\section{Introduction}

Given the incredible boom that the mining industry has enjoyed for more than five years, and the growth opportunities for mining companies from maximising the value of their current mineral assets, it is difficult to imagine that there are topics more important to explore at the present time than strategic and tactical approaches to mining.

Very significant value can be created from a mineral asset if the strategy implemented from the very beginning of the project definition is robust. This strategy will cascade down from the corporate strategy to mine site level. In the early phase of a mining project, the strategy is generally easily implemented. It is when a mine enters the operating phase and becomes more mature that the temptation to deviate from, or even ignore, the strategy in order to achieve short-term gains, can destroy the value of a project.

\section{'High-level' corporate strategy}

"The strategy is the destination whilst the tactic is how you get there" Sunter (2005).

Mining is a highly strategic business. Starting a new mining project is generally investment intensive (potentially billions of dollars), the lead time to bring a prospective ore deposit to production is lengthy (often spans several years), and the potential for creating value is highly dependent on several unknown factors such as the world economy and the future prices of commodities. The risks of achieving a poor outcome are real, however, the reward can be outstanding provided that these risks are controlled and the strategy is robust. Elkington and Grobler (2011),j in a paper published in these proceedings, define a robust strategy as "... a strategy that performs well under a range of scenarios".

At the very First International Seminar on Strategic versus Tactical Approaches in Mining held in South Africa in 2005, Clem Sunter, the Chairman of the Anglo American Chairman's Fund, provided the opening keynote address and explained the five main items that, in his view, companies should base their strategy (Sunter, 2005).

The first item is 'the scope' of the company. The scope is 'pure strategy' and it can be sub-divided into four main components: 
- Product range: define the optimum portfolio of resources the company wants to be involved with. The strategy can focus on one (or few) commodity and rely on a highly specialised core business expertise, or on a diverse portfolio to balance the highs and lows of different commodity prices.

- Product chain: how far down the refinement chain does the company wish to carry its products. The core competency of the business must be tailored to its chain of products.

- Geographical footprint: the decision as to where in the world the company will invest is often a result of the risk/reward strategy adopted.

- Market segment: choosing the product is also choosing the customer as many commodities have very strong market preferences, e.g. iron ore and China.

The second item is 'the players', the players that are with your team. The players that are against your team and those who are neutral. It is particularly important to know the strengths and weaknesses of your team as well as of the competition.

The third item is 'the rules of the game'. A company will have to comply with a different set of rules in different countries. For example, the retention of a license to operate in a country will depend largely on environmental or safety performance and compliance of the company with those rules. There is therefore, a wide range of tolerance to risks from one country to another, including the societal reaction to fatalities and environmental impact.

In addition to the set rules by society, there are also many other rules by which the 'game' can be played, but the strategy must focus on just these few key rules that are essential to win the game. For example, successful mining companies must have good assets (ore deposits). This is an example of one key rule that the strategy must address when operating in the mining business.

The fourth item of a strategy is to account for external pressure and capture opportunities. Factors that drive commodity prices up or down must be well understood and analysed. World events, war, natural disasters, cost of energy, etc., can have a large impact on setting the right strategy.

The fifth item is to tailor the strategy to account for the fluctuation in the 'competitiveness/market' context. If the company's competitiveness is increasing at a time where the market is growing, then the strategy must be bound for fast growth. If the competitiveness is declining as the market is declining, then the strategy must be set on a defence/survival mode. If either one of the competitiveness or the market is up whilst the other is down, then the strategy may, for example, be to grow with a cautious approach to risks.

Subsequently, the tactics that will allow the realisation of the strategy, whilst providing capability to react to new situations, can be established.

These are indeed the very high level strategies and tactics that are owned by the governance of the mining businesses. Looking at the level of individual mines, the company's strategy must cascade down the mine site strategy.

\section{$3 \quad$ Mine site strategy}

Mine strategy is generally about maximising the value of a specific asset, which in this case, consists of exploiting one or several orebodies. It is appropriate to look at the early mining strategy developed and implemented at the project definition stage (conceptual and feasibility studies) and how it may evolve later during the project execution (mine construction and production).

\section{1 Strategic decisions during feasibility and mine design period (project definition)}

The pre-production period is critical as this is when most of the value from an asset can be created or destroyed. This is well illustrated in Figure 2 of Bartlett (2011), a paper published in these proceedings. On 
the hierarchy of decisions taken during the project definition, with regards to creating or destroying value, the selection of the mining method is undoubtedly the most important one. The traditional drivers for choosing the optimum mining method for a given resource are the shape and grade distribution of the orebody and the geotechnical properties of the ore, hangingwall and footwall. This is reflected in a number of guidelines for the selection of mining methods (Hartman, 1987; Boshkov and Wright, 1973; Morrison, 1976; Nicholas, 1981, 1992). These guidelines are summarised in the recently published, "Third Edition of the SME Mining Engineering Handbook" (2011).

In recent years, production rate and unit costs have, to a large extent, replaced orebody characteristics as the main drivers for the mining method selection. Many of the highly selective, low production and higher cost methods, such as cut-and-fill, are now generally applied only in exceptionally poor ground conditions and high grade erratic shaped orebodies. They were progressively replaced since the $1980 \mathrm{~s}$ by the more productive open stoping methods, whose scope of application has been extended from the traditionally competent host rock, to less competent ground by using better ground support techniques and improved design and sequencing. More recently, highly productive and low cost methods such as caving, which were traditionally applied in large footprint massive orebodies with poor geotechnical properties, are increasingly used in smaller footprint and more competent orebodies, sometimes with the aid of preconditioning. Palabora and Northparkes were amongst the first modern mines to use block caving methods in competent ore. A detailed geomechanical assessment of the rock mass properties is essential to enable forecasting off open stope stability, or the cavability and fragmentation of caving mines. The accuracy of these forecasts can make the difference between adding or destroying the value of a project. This is illustrated in the case study found in Mackay (2011).

Some of these strategic decisions taken at the feasibility stage to 'stretch' the applicability of highly productive mining methods beyond the boundary of their traditional applications to potentially increase the value of a mining asset, are taken with the acceptance of an increased risk to the project. The mining industry is becoming more confident at managing these risks, but should they really be?

Even after the mining method is selected, further strategic decisions aimed at maximising project value, sometimes with the result of increasing risk, are taken when the main mine design parameters are selected. For example, the distance between sublevels will have a major impact on the mine development capital cost, and there is an incentive to reduce this cost by maximising the sublevel interval. Reducing the number of sublevels (by maximising the interval) will have a large impact on the net present value (NPV) of a project. However, by setting the sublevel interval, one also sets the height of the stopes. If the stopes are too high and unstable, then the project value will be destroyed by dilution and production delays. Similar decisions are taken with regards to the position of the human and material handling infrastructure, i.e. decline, shaft, footwall drives, orepasses, etc. The closer this infrastructure is positioned to the 'centre of gravity' of the orebody, the lower the future operating costs of the mine. However, the position also needs to account for possible risk of future stability problems due to poor ground conditions, mine induced stresses and unfavourable geometries. An example where the design of the infrastructure has progressively been developed further away from the orebody due to stability issues is shown in Figure 1. 

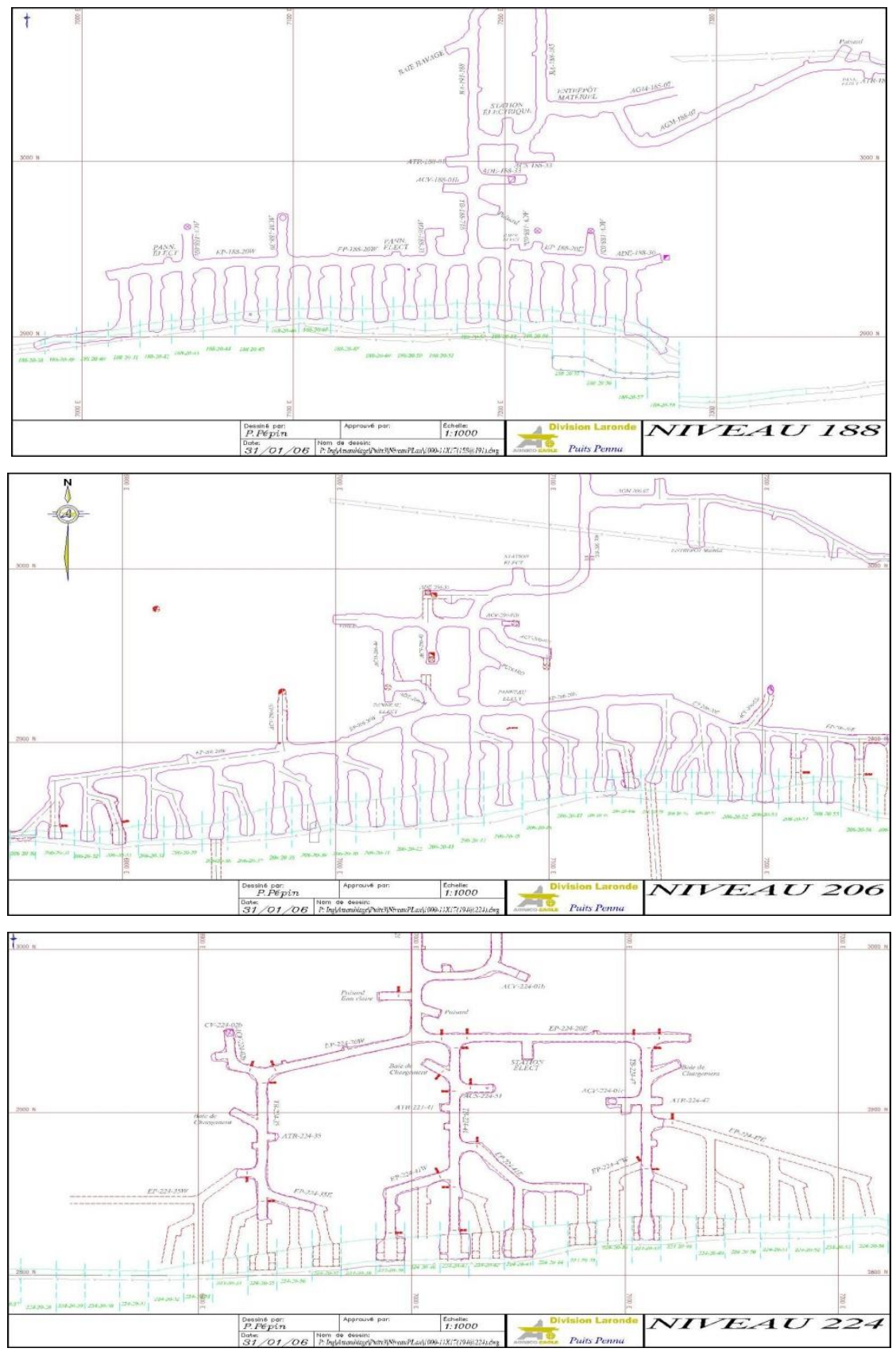

Figure 1 An example from Agnico-Eagle Laronde Mine where the development mining in the footwall has progressively migrated away from the orebody due to mitigated stability issues (reproduced from Mercier-Langevin and Turcotte, 2007)

The aforementioned discussion strongly suggests that most of the risks to destroy value at the early stage of a mining project are linked to strategic mine design decisions that are based largely on geomechanics assessment. Although it is self-evident that obtaining high quality geomechanics data at the early stages of mining projects is a critical part of understanding the risks associated with critical mine design decisions, often the budget and effort required for geomechanics data collection is inadequate. For example, the amount of money spent on geology and orebody definition, which is also a critical risk, is several orders of magnitude higher than the geomechanics budget. Many geomechanics practitioners know how difficult it is to 'sell' to management a comprehensive stress measurements programme in the early stages of mining. The same can be said about obtaining oriented drill core to enable mapping of the joints and structures, which is critical to understand rock mass properties and behaviour. In fact, most geotechnical data is obtained from boreholes designed by geologists for the purpose of defining the orebody rather than to 
understand the geomechanical properties of the rock mass. Most of the drill holes generally originate from the footwall, pass through the orebody and extend until waste rock is encountered, which results in having a poor sampling of stope hangingwalls, as well poor orientation bias. Another potential source of substandard quality data is sometimes linked to geotechnical data collection from core logging being delegated to junior geologists or technicians who have very little (if any) training in geomechanics.

These observations are evidence that the consequences of geomechanics risks related to strategic decisions made during the mine design and pre-production period are often not well understood by the decision makers. The basic mitigation measures of collecting more and better quality geotechnical data can be easily justified, given their role in strategic decision and the potential impact of making the wrong decisions to the creation or destruction of a project's value.

\section{2 Operating mine strategy (project execution)}

Ideally, The corporate strategy would cascade down to the mine strategy, which generally focuses on maximising the value of the asset. There are a number of issues that can derail the implementation of sound mine site strategy and some of them are discussed below.

\section{2. 1 Short-term focus}

Once the mine begins production the infrastructure is in place, the mine layout for the upcoming two to three years is more or less in place, the equipment has been purchased, the plan or strategy is set and the significant part of the focus now becomes tactical. To influence the results positively, only tactical adjustments can be made (for the next couple of years) as a reaction to how the mine performs. For example, changes in ground support may improve stability, equipment availability can improve productivity, and other bottlenecks to production can be addressed.

When production starts and unexpected events occur, a trap mines commonly fall into is to focus uniquely on tactics to achieve short-term targets. Such tactics can sometimes impact negatively on the strategy set and implemented during the feasibility study. In the worst case, the strategy is forgotten or simply abandoned and the actions of mine management are no longer aligned with the long-term operating strategy.

Feeding the short-term focus and driving many of the site behaviours and tactical decisions are the leading key performance indicators (KPIs) at mine sites, which, in addition to safety, are sometimes narrowly focussed on the quantity of minerals extracted (ounces, tons) on a monthly and annual basis. Such production KPIs, in combination with the rapid turnover of managerial personnel at mine sites (in Australia), provide a strong incentive to ignore the long-term value adding actions in favour of short-term gains.

Examples of this are easy to find in underground mines. Let's consider the case of a mine ' $A$ ' that has a 'strict' mining sequence to manage the mine induced stresses. As the mine encounters severe problems with two stopes and cannot meet production targets for the next few months, a decision is taken to bring two new stopes into production early and out of sequence (which can be drilled and charged rapidly) to compensate for the forecasted production loss. A year later, the change in sequence causes high stress problems in several stopes and in the infrastructure, and the solution to the short-term production problem of last year becomes the origin of a long-term and more severe problem.

Mine ' $\mathrm{B}$ ' also has a tight sequence to manage mine induced stress and uses paste fill in the primary stopes to allow mining of the adjacent secondary stopes. A major problem occurs at the paste fill plant which will be down for several weeks and management is faced with the following options:

1. Delaying production as cemented fill cannot be placed.

2. Filling primary stopes with uncemented fill which will sterilise part of the secondary stopes. 
3. Continuing with mining of more primary stopes and create more voids. Given the plant production capacity, this means that catching up with the filling schedule will not be possible in the future.

Options 2 and 3 will allow short-term production targets to be met, but they will create severe long-term problems and increase the risk of future production. This is another example where the tactical solution of a short-term problem is not aligned with the long-term strategy to maximise the value of the project.

Another common KPI that often drives management decisions, which is not always conducive to maximising the value of assets if implemented within a short-term gain approach, is a target unit cost of ore. The incentive to cut costs for the sake of meeting a short-term KPI may have a significant long-term value reduction effect. There are numerous common cost-cutting examples in underground mines, where expenses such as the purchasing or upgrading of new equipment is delayed, the development of the mine's more expensive area is differed, hiring of personnel focussing on long-term tasks is cancelled, etc. However, the real long-term impact of these short-term driven actions to reduce cost often destroys some of the value of the project several months or years later.

\subsection{Defining the resource}

The mine site strategy is generally maintained and implemented through the long-term planning process, which often involves a 'rolling' five year plan, where the reserves are renewed in blocks, in a systematic and optimum fashion. For many smaller companies and mines, the resources are often not well defined ahead and they are progressively transformed into reserves as mining progresses. The mine is then continuously operated in a short mine-life focus, where little or no dedicated effort is spent on the long-term (say five year horizon) planning and no significant investment is made with the purpose of increasing productivity or lowering the long-term mining costs. For example, there are cases of companies continuing to use truck haulage in mines that are increasing in depth, instead of constructing a shaft hoisting system to reduce the operating cost in the long-term, because there are never enough reserves identified ahead. This is a result of a lack of site strategy and incomplete realisation of the real value of the assets in the long-term.

Other examples of mine infrastructure improvements that can never be justified include a second decline, a fill plant, new equipment, etc., because the continuous renewal of the two year remaining mine life is insufficient to reimburse for any new substantial investments. It is not uncommon to visit mines that have been operating on a two year mine life, for the last 10 years. This is particularly common in small Western Australian mines, where the transition from open pit to underground is incremental. Underground mining in these cases, begins from the bottom of the pit progressing downward. The orebody is generally open at depth, the resource is unknown and small blocks are transformed into mineable reserves in incremental slices of one or two years. This minimises the capital expenditure, which suits smaller companies with limited capacity to raise capital, but negates the potential economic advantages of developing an infrastructure suitable to the 'real orebody' which is unveiled and mined incrementally, small blocks at a time. The real value of these assets is never fully realised. Therefore, it is not only important to define reserves well ahead of mining, but also to assess a range of outcomes using a proper economic analysis to better understand the sensitivity of different parameters and define their financial impact.

\subsection{Strategic initiatives}

As mine production evolves, the hypotheses from the pre-feasibility are being tested and new knowledge is acquired by observing and measuring the rock mass response and the performance of the operation. Strategic initiatives during the execution of the project provide an opportunity to use the newly acquired knowledge to re-assess the mine plan and identify opportunities and options that can optimise the design and add value in the medium- and long-term.

The implementation of a comprehensive monitoring programme at the early stage of production will facilitate the understanding of the rock mass response to mining and accelerate the optimisation process of the mine design. As the mine becomes more mature, the opportunity to optimise mine design diminishes, 
but the geomechanics hazards often increase due to the high extraction ratio and often elevate mine induced stresses. The emphasis of implementing a monitoring programme is to help understand and quantify potential risks, and develop timely mitigation measure against these geomechanics hazards. The aim of an instrumentation programme at that stage is to provide early warnings that will allow the implementation of corrective actions.

\section{$4 \quad$ Summary and conclusion}

This paper discusses some aspects of strategic and tactical approaches to mining derived from observations by the author. The main items of a corporate strategy, based on the keynote given by Clem Sunter (2005) at the first seminar of the series on Strategic versus Tactical Approaches in Mining, are briefly described. Some aspects of mine site strategies, from feasibility to production, are presented with an emphasis on some of the traps that mines can fall into.

A strong geomechanics input into long-term planning is essential as the major risks of not achieving the plan is in most cases related to the mismanagement of geomechanics hazards. The management of geomechanics hazards, whether high stress and seismicity, uncontrolled caving and dilution, and excessive rehabilitation work, is best addressed pro-actively with the selection of an appropriate mining method, a mining sequence that minimises high induced stresses and stope dimensions that will remain stable. There are other essential geomechanics issues that require pro-active management to achieve the long-term plan and strategy. They include the adequate filling of stopes and the maintenance of orepass stability. The implementation of a mining method, a mining sequence, stope dimensions, filling requirement and orepasses stability that suits the conditions, requires a long lead time and cannot be changed easily, once the infrastructure is in place. The importance of optimising these geomechanics components of mine design in the first instance, followed by a proper monitoring programme implementation, is vital. Therefore, part of the strategy must have provision to enable sufficient up-front geomechanics investigations to obtain data of adequate quality and quantity, which is essential to produce robust designs that mitigate and/or reduce geomechanics risks. The linkage of the possible financial impacts of short-term tactical decisions to a realistic economic valuation will improve the ability of management to make informed decisions on a range of future outcomes.

In concluding this short overview of strategic and tactical approaches, it is important to mention that one of the underlying strategic issues which was not discussed in this paper, but affects all aspects of the industry, is people and, more specifically, for the last decade or so the shortage of skilled people. In a keynote presented at The AusIMM Underground Operators' Conference in March 2011 in Canberra, Ian Smith, CEO and managing director of Newcrest Ltd at the time, showed that although Australia will produce 1,200 mining engineers over the next five years, this will leave a shortfall of 1,700 mining engineers during the same period (Smith, 2011). This introduces another risk to project definition and execution and the possibility of realising the corporate and mine site strategies.

\section{References}

Bartlett, P. (2011) Strategic and tactical risk in mining, in Proceedings from the Fourth International Seminar on Strategic versus Tactical Approaches in Mining, Y. Potvin (ed), Perth Australia, 8-10 November 2011, pp. 349-358.

Boshkov, S.H. and Wright, F.D. (1973) Underground mining systems and equipment, in SME Mining Engineering Handbook, A.B. Cummins and I.A. Given (eds), New York, SME-AIME.

Elkington, T.J. and Grobler, F.C. (2011) Robust mine planning, in Proceedings from the Fourth International Seminar on Strategic versus Tactical Approaches in Mining, Y. Potvin (ed), Perth Australia, 8-10 November 2011, pp. 11-20.

Hartman, H.L. (1987) Introductory Mining Engineering, Wiley, New York, 633 p.

Mackay, D. (2011) Implementing and Improving the Mine Plan at the Mt Wright Project, in Proceedings of the 11th AUSIMM Underground Operators' Conference, The Australian Institute of Mining and Metallurgy, Canberra, pp. 135-142.

Mercier-Langevin, F. and Turcotte, P. (2007) Expansion at depth at Agnico-Eagle's Laronde Division - Meeting geotechnical challenges without compromising production objectives, in Challenges in Deep and High Stress Mining, Y. Potvin, J. Hadjigeorgiou and D. Stacey (eds), Australian Centre for Geomechanics, Perth, pp. 189-195.

Morrison, R.G.K. (1976) A Philosophy of Ground Control, A Bridge Between Theory and Practice, Revised edition, Montreal, QC: McGill University, Department of Mineralogy, Metallurgy and Engineering, $182 \mathrm{p}$. 
Nicholas, D.E. (1981) Method selection - A numerical approach, in Design and Operation of Caving and Sublevel Stoping Mines, D. Stewart (eds), New York: SME-AIME.

Nicholas, D.E. (1992) Selection procedure, in SME Mining Engineering Handbook, 2nd edition, H.L. Hartman (ed), Littleton CO: SME, Vol. 2.

SME (2011) Mining Engineering Handbook, Society of Mining, Metallurgy and Exploration, Inc., 3rd edition, P. Darling (ed), Vol. 1.

Smith, I. (2011) Keynote in Proceedings of the AusIMM 11th Underground Mine Operators' Conference, 21-23 March 2011, Canberra, ATC, Australia, unpublished presentation.

Sunter, C. (2005) Keynote presented at the First International Seminar on Strategic versus Tactical Approaches in Mining, The South African Institute of Mining and Metallurgy Symposium Series 40, September 2005, Sandton, verbal keynote only. 